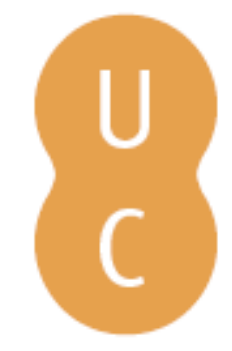

\title{
Rombalina
}

\section{Risco ambiental e vulnerabilidade: discussão conceitual a partir de trabalhos de conclusão de curso em Belo Horizonte - Minas Gerais/Brasil}

\author{
Autor(es): $\quad$ Souza, Carla Juscélia de Oliveira \\ Publicado por: Imprensa da Universidade de Coimbra; RISCOS - Associação \\ URL \\ persistente: \\ Portuguesa de Riscos, Prevenção e Segurança \\ DOI: $\quad$ DOI:http://dx.doi.org/10.14195/978-989-96253-3-4_4 \\ Accessed : $\quad$ 26-Apr-2023 14:08:09
}

A navegação consulta e descarregamento dos títulos inseridos nas Bibliotecas Digitais UC Digitalis, UC Pombalina e UC Impactum, pressupõem a aceitação plena e sem reservas dos Termos e Condições de Uso destas Bibliotecas Digitais, disponíveis em https://digitalis.uc.pt/pt-pt/termos.

Conforme exposto nos referidos Termos e Condições de Uso, o descarregamento de títulos de acesso restrito requer uma licença válida de autorização devendo o utilizador aceder ao(s) documento(s) a partir de um endereço de IP da instituição detentora da supramencionada licença.

Ao utilizador é apenas permitido o descarregamento para uso pessoal, pelo que o emprego do(s) título(s) descarregado(s) para outro fim, designadamente comercial, carece de autorização do respetivo autor ou editor da obra.

Na medida em que todas as obras da UC Digitalis se encontram protegidas pelo Código do Direito de Autor e Direitos Conexos e demais legislação aplicável, toda a cópia, parcial ou total, deste documento, nos casos em que é legalmente admitida, deverá conter ou fazer-se acompanhar por este aviso.

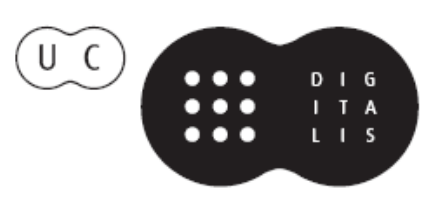



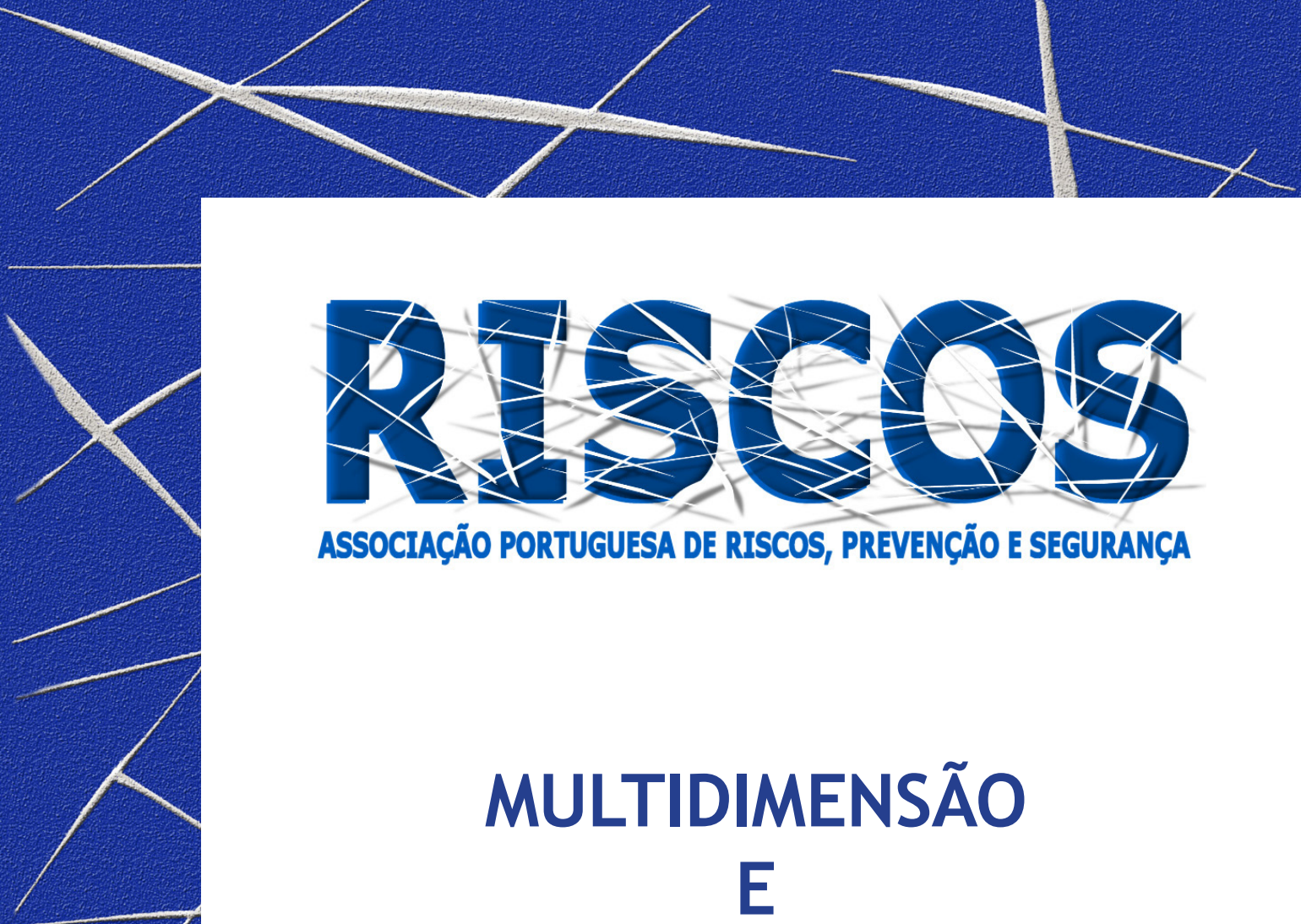

ASSOCIAÇÃO PORTUGUESA DE RISCOS, PREVENCCÃO E SEGURANÇA

MULTIDIMENSÃO

E
TERRITÓRIOS DE RISCO

III Congresso Internacional

I Simpósio Ibero-Americano

VIII Encontro Nacional de Riscos

Guimarães

2014 


\title{
RISCO AMBIENTAL E VULNERABILIDADE: DISCUSSÃO CONCEITUAL A PARTIR DE TRABALHOS DE CONCLUSÃO DE CURSO EM BELO HORIZONTE - MINAS GERAIS/BRASIL
}

\author{
Carla Juscélia de Oliveira Souza \\ Departamento de Geociências, Curso de Geografia. \\ Universidade Federal de São João del-Rei/MG, Brasil \\ carlaju@ufsj.edu.br
}

\begin{abstract}
RESUMO
A escola, tempo e espaço para educação básica de criança e jovem brasileiros, move-se em direção à construção de sujeitos cidadãos. O movimento compreende ações diversas, entre elas o ensino e aprendizagem de conteúdos significativos organizados em disciplinas escolares. Atentos a esses princípios, trabalhos de conclusão de curso (TCC) e propostas didático-pedagógicas que considerem a temática "Áreas de risco socioambiental" têm sido desenvolvidos no âmbito acadêmico, a partir de realidades locais e de escolas públicas de Belo Horizonte. Este texto apresenta e discute o tipo de abordagem e os conteúdos referentes a riscos presentes em três trabalhos de TCC. Nessa discussão foram considerados os conceitos vulnerabilidade, perigo e risco, importantes na literatura referente a Riscos. Cada um dos trabalhos analisados contemplou a questão "Risco" de maneira direta ou indireta em pesquisas que consideraram abordagem do tema pelas perspectivas da percepção ambiental, da concepção de riscos e dos saberes escolar. Nas áreas onde os três estudos foram realizados existe o risco de inundação no entorno das escolas e na vila Bacuraus. Na discussão foram valorizados a importância e o papel social da geografia escolar. A análise e discussão desses trabalhos mostraram possibilidades didático-pedagógicas com assuntos que podem ser desdobrados do tema, mas, também, a necessidade de mais leituras e fundamentação teórica sobre o tema risco.
\end{abstract}

Palavras-chave: Risco, Escola e Geografia.

\section{Introdução}

O trabalho compreende a análise conceitual dos termos área de risco ambiental e vulnerabilidade presentes em três Trabalhos de Conclusão de Curso (TCC), na área da Geografia, realizados no período de 2010 a 2011, em universidade de Belo Horizonte. Os TCC's abordaram os assuntos "Saberes de geografia física no cotidiano da escola; Concepção de risco socioambiental entre alunos do ensino médio e Percepção ambiental da população da vila Bacuraus". O objetivo, de retomar os referidos trabalhos, foi o de verificar a concepção dada aos termos risco ambiental e vulnerabilidade nos trabalhos. Em eventos diversos da Geografia, verifica-se aplicação genérica e às vezes inadequada do uso dos termos riscos ambiental e vulnerabilidade em diversos trabalhos acadêmicos. Portanto, tem-se esse fato como uma das hipóteses a ser verificada.

Os trabalhos selecionados foram desenvolvidos com sujeitos da Escola Estadual Conceição Martins de Jesus (Trabalho 1) e da Escola Municipal Secretário Humberto Almeida (Trabalho 2) e, ainda, com moradores da Vila Bacuraus (Trabalho 3), na cidade de Belo Horizonte. Para a análise dos conceitos risco ambiental e vulnerabilidade presentes no referidos trabalhos adotouse a metodologia da análise do conteúdo, com leituras direcionadas, a fim de: i) Inteirar do conteúdo geral dos trabalhos de TCC; ii) Verificar a presença ou não da discussão dos termos risco, vulnerabilidade, e a concepção apresentada pelos sujeitos da pesquisa; iii) Identificar o tipo de abordagem, se percepção, concepção e ou representação sobre o assunto, pelos sujeitos. Durante as leituras, aproveitou-se para identificar expressões, exemplos e citações 
que pudessem ser resgatadas durante a análise dos conteúdos qualitativos. Durante as discussões dos dados qualitativos e da análise dos trabalhos outros conceitos foram considerados, como perigo, cidadania, saberes e paisagem, considerados importantes na abordagem referente à tríade Riscos, Educação e Ensino de geografia, conforme discutido por Souza (2013).

0 trabalho um (1) abordou a concepção de risco ambiental entre alunos do ensino médio, especificamente alunos do terceiro ano, em 2010. O objetivo foi o de investigar qual era a concepção de risco ambiental existente entre alunos, utilizando para essa investigação o recurso didático maquete (Figuras 1 e 2 ).
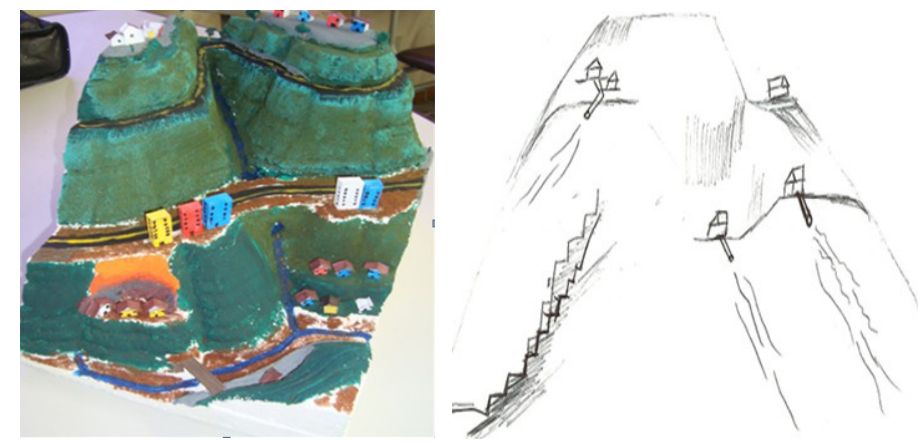

Figura 1 e 2: Maquete hipotética e representação de área de risco do grupo 2. Fonte: GUIMARÃES E PEREIRA, 2010.

O trabalho dois (2) contemplou o assunto "Saberes de geografia física no cotidiano da escola e potencial de risco no contexto escolar" e foi realizado com professor de geografia e alunos do $9^{\circ}$ ano, da Escola Municipal Secretário Humberto Almeida, em 2011 (Figura 3). 0 estudo do meio da área do entorno dessa escola possibilita discussões in loco a respeito de dinâmica fluvial, crescimento urbano, uso e ocupação do terreno, perigos, vulnerabilidade dos sujeitos e edificações e dos riscos ambientais.

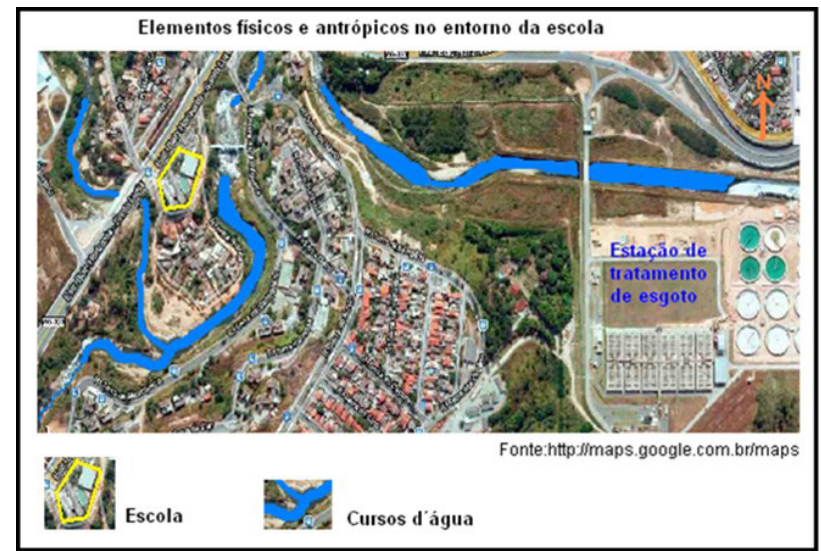

Figura 3: Ambiente no entorno da escola

Fonte: SANTOS et. al (2011) 
0 trabalho três (3), referente à Percepção ambiental da população da vila Bacuraus teve como objetivo verificar a percepção sobre riscos ambientais dos moradores e a relação que eles têm com o lugar onde moram (Figura 4). A vila foi revitalizada em 2005, o córrego retificado e novas residências construídas para a população ribeirinha. A população preferiu ficar no local e ocupar as novas edificações.

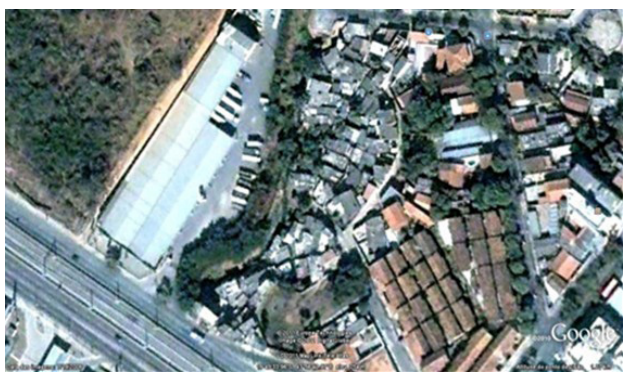

Figura 4a (1999)

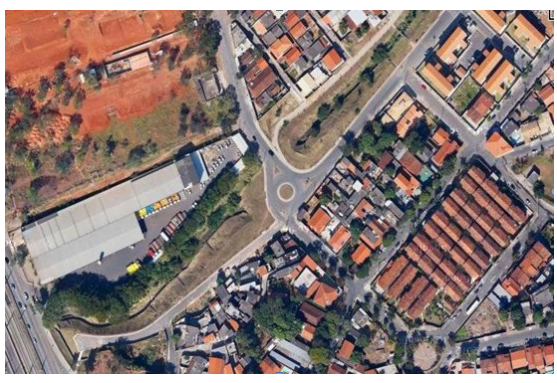

Figura 4b (2011)

Figuras 4a e b: Vila bacuraus antes e depois da revitalização.

Fonte: FARA e QUINTÃO, 2011.

\section{Discussão dos termos risco e vulnerabilidade nos trabalhos}

Os trabalhos um (1) e três (3) contemplaram a questão "Risco" de maneira direta ao fazerem perguntas e abordagens sobre o assunto aos seus entrevistados. Em ambos, a ideia de risco refere-se à questão da combinação da presença humana próximo a canais de drenagem e, ou ocupando encostas. Nota-se uma concepção limitada do termo Risco. Sobre a concepção de risco ambiental, os autores mostraram que o grupo (1), alunos mais velhos (32 a 40 anos), fundamenta tal concepção na definição de degradação ambiental ocasionada pela ação humana, conforme é mostrado nas citações seguintes: "[...] a exploração inadequada do solo e a degradação da natureza"; "[...] o risco ambiental e mau utilização do solo que vem causando vários tipos de erosão" e "[...] falta de coleta de lixo seletiva, pois alguns tipos de lixos contaminam o solo". Essas falas referem-se à ideia de degradação ambiental e suas causas e não exatamente à ideia de risco, qual seja a da exposição humana a perigos de ordem natural, combinados com os sociais e tecnológicos que possam desencadear risco de perda de vidas e/ou bens materiais. Já os alunos mais jovens, grupo 2, com idade entre 18 e 20 anos, relacionaram o risco ambiental a fenômenos naturais e a situações induzidas pelo homem, as quais causam efeitos negativos sobre o próprio homem (Figuras 1 e 2), como cortes e ocupação de terrenos íngremes.

Nas respostas dos sujeitos do grupo 2, constata-se que a ideia de risco ambiental refere-se aos riscos de deslizamento e inundações, para maioria dos entrevistados. E, de acordo com esses sujeitos (100\%), a vulnerabilidade se dá devido à localização dos sujeitos na área considerada de risco, conforme se observam nas frases elaboradas pelos sujeitos entrevistados: [...] "para pessoas que moram próximo ao rio por causa das enchentes"; [...] "inundação de água nas casas que estão em áreas de risco"; [...] "a estrada também porque se um carro estiver passando e estiver chovendo e cai um pedaço de terra a pessoa está correndo risco" e [...] a "construções em locais onde há deslizamentos e casas próximas ao rio e perto de estrada de rodagem". 
A noção de risco ambiental, que considera a perspectiva social de apropriação do espaço pela sociedade, a interação dos efeitos dessa apropriação e a dinâmica dos fenômenos naturais revelam a complexidade existente na ideia de riscos ambientais, apesar de geralmente ser simplificada nos estudos observados. Nota-se a falta de clareza entre termos como risco, perigo, vulnerabilidade, áreas de riscos, mas o senso comum. A ideia de vulnerabilidade como sendo a da exposição geográfica do alvo ao perigo foi a única presente na discussão dos trabalhos (1) e (3). 0 trabalho dois (2), apesar de não ter como foco a questão de área de risco, quando aborda os conteúdos de geografia física na escola básica e os saberes do professor, revela dentro da questão ambiental a ser explorado pela geografia escolar, as condições da dinâmica fluvial e a existência de áreas de risco no entorno escola. Esse risco se deve à interação dos aspectos, alvo, perigo e vulnerabilidade, como colocado por Veyret (2013). A vulnerabilidade, indicada nesse caso, relaciona-se à localização geográfica dos alvos, assim como apontado, também, pelos sujeitos das pesquisas um (1) e (3).

Em todos os trabalhos nota-se que a ideia de vulnerabilidade apoia-se principalmente como exposição direta do alvo ao perigo local, como encostas íngremes e inundações dos cursos d'água, o que leva ao risco de perdas humanas e materiais. Essa ideia corresponde a uma das possibilidades de se entender o conceito de vulnerabilidade, o qual é amplo e variado, portanto complexa. Para Dauphiné (2001) apud Veyret (2013, p.393), vulnerabilidade "exprime o grau das consequências previsíveis geradas por um fenômeno natural e que podem afetar o alvo". Nota-se nas definições que vulnerabilidade compreende a análise estimativa dos danos potenciais que podem afetar o alvo e não somente a exposição geográfica do alvo. $\mathrm{Na}$ análise são levados em consideração outros aspectos como ausência ou não de infraestrutura, condições estruturais das edificações, a capacidade de resposta institucional, condições socioeconômicas da população alvo (VEYRET, 2013) e à própria representação e percepção de risco por parte dos sujeitos e o conhecimento sobre o assunto.

\section{Conclusão}

A análise e discussão de trabalhos elaborados como TCC mostraram que existem interesses de graduandos pela discussão da temática "riscos ambientais" pela perspectiva geográfica, tanto no âmbito do estudo de caso, como aconteceu com o trabalho na Vila Bacuraus, quanto no âmbito da geografia escolar. Neste âmbito, os conteúdos presentes na temática mostraram possibilidades didático-pedagógicas, como o estudo de área do entorno da escola, por meio do método estudo meio, de visita orientada, ou de pesquisa e trabalhos com fotografias e imagens de satélites disponíveis na internet, como as do Google, entre outras. Além disso, o levantamento e análise do conteúdo e da temática trouxeram à tona, durante diálogos sobre riscos e educação no interior deste trabalho, a importância e a necessidade de se considerar a temática "riscos ambientais" no contexto escolar, principalmente pelos caminhos da geografia. De acordo com Veyret (2013) uma verdadeira educação sobre os riscos é capaz de reduzir a vulnerabilidade. As análises possibilitaram, também, constatar que os autores dos TCC's ao optarem trabalhar com o tema "riscos" e "risco ambiental" realizaram breves leituras gerais sobre o referido tema, atentando-se para definições e alguns autores conhecidos, não constituindo uma revisão bibliográfica sobre o assunto. A iniciativa para se trabalhar de maneira aplicada tal tema a estudo de caso e ou a propostas escolares é bem vinda e deve ser estimulada. Mas, são necessárias mais leituras sobre o tema "riscos" com abordagem conceitual. Essas leituras e discussões no âmbito acadêmico ainda são recentes e limitadas a alguns cursos de graduação 
em Geografia, no Brasil. Acredita-se que a iniciativa de eventos como o III Congresso Internacional, I Simpósio Ibero-americano, II Encontro Luso Brasileiro de riscos contribua para que mais leituras e discussões sobre a temática riscos sejam ampliadas e aprofundadas.

\section{Bibliografia}

DAUPHINÉ, André. Risques et catástrofes: observer, spatialiser, compreendre, gérer. Paris: Armand Colin, coll. 2001.

FARAH, Aline M. e QUINTÃO, Renata C. Um estudo sobre a percepção ambiental da população da região da Vila Bacuraus. Belo Horizonte: UNIBH, (Trabalho de conclusão de curso. Geografia), 16p, dez. 2011

FERNANDES, Bruno de Jesus; ROCHA, Geraldo César. Educação sobre riscos ambientais: uma proposta metodológica. Virtú (UFJF), v. 4, p. 01-15, 2007.

GUIMARÃES, Lucas V. e PEREIRA, Luciana M. Levantamento da concepção de risco ambiental entre alunos de geografia do ensino médio por meio do uso de maquete. Belo Horizonte: UNIBH (Trabalho de conclusão de curso. Curso de Geografia), 20p, dez. 2010.

SANTOS, Bruno F. dos; Rocha, Charles O. e SANTOS, Varlei B. dos. Saberes da Geografia física no cotidiano da escola. Belo Horizonte: UNIBH (Trabalho de conclusão de curso. Geografia), 20p, jun. 2010.

SOUZA, Carla J. O. "Área de risco socioambiental nas cidades: prática educativa na formação docente e na geografia escolar”. In: VI Congresso Ibérico de Didática de Geografia. Anais... VI Congresso Ibérico de Didática de Geografia. Porto, Portugal, p.563-575, mar.2013.

VEYRET, Yvette. Os riscos - o homem como agressor e vítima do meio ambiente. São Paulo: Contexto, 2013. 